\title{
Endoscopic clips: Past, present and future
}

\author{
Joseph Romagnuolo MD FRCPC MSc
}

\begin{abstract}
A form of the metal clip (also known as a 'hemoclip' or 'endoclip') for flexible endoscopes has now been available for more than 15 years (1), with early versions presented more than 30 years ago (2). Although uptake was initially slow, clips have made their way into standard gastrointestinal endoscopic practice for common indications, such as ulcer (3), Mallory-Weiss tear $(4,5)$, diverticular bleeding $(6,7)$, or bleeding or high-risk (8-10) polypectomy sites. They are also increasingly being used for uncommon indications, such as securing stents $(11,12)$, feeding tubes (13) and other devices; marking of endoscopic lesions for $\mathrm{x}$-ray or magnets $(14,15)$; closing fistulas as presented in the article by Hameed et al (16) in this month's Journal (pages 217-219); and perforations (17), including sealing the luminal entry site in experimental natural orifice transluminal endoscopic surgery (NOTES) (18). The indication with the highest level of evidence at the present time is clearly ulcer hemostasis (3), but animal models and case series of other indications are rapidly accumulating.
\end{abstract}

\section{DIFFERENT TYPES OF ENDOSCOPIC CLIPS}

The first clip in widespread use (1995) was manufactured by the Olympus Corporation (Japan). Although initially a reusable rotatable device that required manually reloading a disposable clip onto a small hook at the end of a metal cable running through a plastic sheath, the disposable preloaded versions of this clip (Quickclip, 2002; and the rotatable Quickclip2, 2005 [Olympus Corporation, Japan]) are presently more commonly used. The preloaded version is easier and faster to use, especially in the setting of a bleeding lesion. These two-pronged clips are available in different clip arm lengths, resulting in varied diameters of tissue ( $5 \mathrm{~mm}$ to $11 \mathrm{~mm}$ ) that can be clipped (19). It can be rotated to align the clip arms to the tissue that the operator wishes to grasp, by rotating the handle. Deploying the clip requires: advancing the clip out of the sheath, at which point the clip partially opens; squeezing the trigger part of the way (which opens the clip to its maximum diameter, often referred to as 'priming' the clip [Note, if the trigger is squeezed too far, the clip will start to irreversibly close]); advancing the clip catheter through the accessory channel until it is firmly against the tissue (keeping the clip tip to within $2 \mathrm{~cm}$ to $4 \mathrm{~cm}$ of the scope tip, to avoid the catheter from bowing or bending. This may prevent the clip from firing); rotating the clip if needed; and then squeezing the trigger the rest of the way, closing the clip until a 'click' is heard and felt. The clip cannot be reopened. The clip is now deployed and should unhook spontaneously from the inner cable. The catheter can now be removed from the scope. However, care should be taken not to remove the catheter until assured the clip is free from the hook on the inner cable; otherwise, the vessel that has been just clipped may be sheared off when the catheter is withdrawn. Occasionally, a 'jiggle' of the catheter is needed for the clip to be freed from the apparatus.

Another device, introduced by Cook Endoscopy (Cook Medical Inc, USA) in 2003, is the TriClip. This is the only threepronged clip available, and opens quite wide (12 $\mathrm{mm}$ diameter) but tends to have a lower radial grasping force than the other devices. The three prongs may make grasping protruding lesions - such as a polypectomy stalk easier, and rotation is not necesssary because of the three prongs. It also brings three edges of tissue together and may reduce the number of clips needed. Its shape is immediately familiar to endoscopists who have used the three-pronged foreign-body removal device. The original version has a flushing port, but requires a therapeutic channel and is somewhat bulky. Although preloaded, the clip is initially exposed from the sheath when removed from its shipping package. The card that separates the clip spool (end of the handle) and the stem grip should not be removed - this card prevents the clip from deploying prematurely. Before inserting the catheter into the endoscopic channel, the sheath is unscrewed from the handle, then advanced while guiding the clip as it collapses into the sheath. Once the catheter is exposed in the patient at the tip of the scope, this action is reversed by pulling back the sheath and screwing it back in place, exposing the clip. Now ready to deploy, the card is removed (what some call the 'grenade pin') and the clip spool is pushed toward the stem grip until the clip is closed. As with the endoscopic clip manufactured by Olympus, it cannot be reopened. The clip spool is then pulled back to release the clip. Once the operator is sure it is released, the sheath can be pulled back into the scope.

Another device - the Resolution Clip - is manufactured by the Boston Scientific Corporation (USA). This is a twopronged clipping device that boasts the ability to open and close the clip before finalizing deployment. It is preloaded and has a clip jaw span of $11 \mathrm{~mm}$. Once in the patient, the stopper

Medical University of South Carolina, Charleston, South Carolina, USA

Correspondence: Dr Joseph Romagnuolo, Medical University of South Carolina, 25 Courtenay Drive, ART 7100A, MSC29,

Charleston, South Carolina 29425, USA. Telephone 843-876-4261, fax 843-876-7232, e-mail romagnuo@musc.edu

Received and accepted for publication February 6, 2008 
is removed and the over-sheath grip is pulled back, exposing the clip. The trigger handle can then open and close the clip a few times (up to five times) until the operator is satisfied with the grasp of the tissue, firmly squeezing to finalize deployment, and then releasing the clip from the sheath similar to the other devices above.

Multifiring clip devices are also being developed. One device (which was recently withdrawn) is the Multi-Clip, manufactured by InScope Inc (Ethicon Endosurgery, USA). It has an outer jaw that contains four separate two-pronged titanium clips (all of the clips described above are stainless steel) within it. The outer jaw can open and close and is rotatable, and four clips can be applied without reloading. It requires a therapeutic channel. A German company has also been developing a new disposable clipping device (Clipmaster3; Medwork GmbH, Germany). It allows for the application of three clips (two-pronged) without changing the device.

A few studies comparing some of these devices head-to-head reveal no dramatic differences in apparent efficacy (20). Most of these studies were conducted in experimental models rather than in human clinical settings. The Triclip may have a lower initial hemostasis rate $(21,22)$, but others have not shown a difference (23); the TriClip may also have a shorter retention time in animal models (24). Clinically important differences between the different types of devices have not been clearly demonstrated.

\section{TIPS}

All of the clipping devices work more effectively when the distance between the scope tip and the tissue is minimal, which maximizes the translation of force to the tissue. As well, maintaining the catheter perpendicular to the wall (ie, minimizing a tangential approach) is very important. Clipping lesions that are not accessible with the above concepts should not be attempted because more damage can result if the clip 'biopsies' a vessel, rather than clips it. Cautery and injection devices or argon plasma coagulation may work better in these difficult-to-access areas. Working in a retroflexed position can make deployment difficult, but it is often better if the clip is out of the scope before retroflexing. A plan of attack should be ready before opening and exposing the clip; 'waving' an open clip may scrape the lesion or dislodge it prematurely, and should be avoided. Finally, all of the clipping devices are awkward to use with a side-viewing duodenoscope. Minimal elevator action should be used and if needed, the outer sheath of the Resolution clip can be removed.

\section{REFERENCES}

1. Binmoeller KF, Thonke F, Soehendra N. Endoscopic hemoclip treatment for gastrointestinal bleeding. Endoscopy 1993;25:167-70.

2. Hayashi T, Yonezawa M, Kawabara T. The study on staunch clip for the treatment by endoscopy. Gastroenterol Endosc 1975;1975:92-101.

3. Sung JJ, Tsoi KK, Lai LH, Wu JC, Lau JY. Endoscopic clipping versus injection and thermo-coagulation in the treatment of non-variceal upper gastrointestinal bleeding: A meta-analysis. Gut 2007;56:1364-73.

4. Huang SP, Wang HP, Lee YC, et al. Endoscopic hemoclip placement and epinephrine injection for Mallory-Weiss syndrome with active bleeding. Gastrointest Endosc Clin N Am 2002;2002:842-6.

5. Cho YS, Chae HS, Kim HK, et al. Endoscopic band ligation and endoscopic hemoclip placement for patients with Mallory-Weiss syndrome and active bleeding. World J Gastroenterol 2008;14:2080-4.

6. Yen EF, Ladabaum U, Muthusamy VR, Cello JP, McQuaid KR, Shah JN. Colonoscopic treatment of acute diverticular hemorrhage using endoclips. Dig Dis Sci 2008;53:2480-5.

\section{INDICATIONS}

As stated above, it is clear that endoscopic clips are an acceptable option for ulcer bleeding (3) and are likely an effective option for vascular lesions such as Dieulafoy's lesions and Mallory-Weiss tears $(4,5)$. Endoscopic clips may be useful to prophylactically close mucosal defects after endoscopic mucosal resection (25) or high-risk polypectomy cases (such as those that require restarting antiplatelet or anticoagulant therapy) (9,26). Securing stents (27) and feeding tubes $(28,29)$ have also been described, but effectiveness at preventing migration beyond a short time is not clear.

Evidence of the effectiveness of clips for the endoscopic closure of fistulas and perforations is growing (16). Clipping perforations appears feasible and safe (17), especially after polypectomy or mucosal resection (30); however, one must weigh one's comfort and speed with this technique, and the appropriateness of the site and size of defect, with the delay to possible surgical treatment or added air introduced through the perforation. Chronic fistulas are often fibrotic and it may be difficult to bring the edges together. Encouraging the edges of the fistula to seal by inducing a mucosal injury before clipping either with argon plasma coagulation (31) or contact cautery (32) may be helpful, but not critical (33). Various sealants have also been used as an adjunct to endoclips $(34,35)$, building on almost 20 years of case reports of sealants used without clips (36).

We have used endoscopic clips to successfully seal $10 \mathrm{~mm}$ to $12 \mathrm{~mm}$ gastrotomies during NOTES procedures in a porcine survival model. Clips appear more effective, but is more feasible in these larger holes when used to clip a detachable snare to the edges of the hole, and then cinching the hole closed with a purse-string technique, rather than trying to clip the widespread edges together (18).

\section{SUMMARY}

Endoscopic clips are an invaluable tool with a wide and expanding range of applications. The future is wide open for endoscopic clips. Refinements in the technology (longer or controllable adherence, larger diameters and transmural penetration, etc) and creative expansions in the indications, promise to greatly expand what can be accomplished with a flexible endoscope in the next decade. Even a wirelessly steerable and deployable capsule clip has been recently described (37) and so there appears to be unlimited potential in clip technology for the gastroenterologist in the years to come.

7. Simpson PW, Nguyen MH, Lim JK, Soetikno RM. Use of endoclips in the treatment of massive colonic diverticular bleeding. Gastrointest Endosc 2004;59:433-7.

8. Letard JC, Kaffy F, Rousseau D, Nivet JM. [Post-polypectomy colonic arterial hemorrhage can be treated by hemoclipping]. Gastroenterol Clin Biol 2001;25:323-4.

9. Shioji K, Suzuki Y, Kobayashi M, et al. Prophylactic clip application does not decrease delayed bleeding after colonoscopic polypectomy. Gastrointest Endosc 2003;57:691-4.

10. Harewood GC. Prophylactic clip application after colonic polypectomy. Gastrointest Endosc 2007;65:183.

11. Sebastian S, Buckley M. Endoscopic clipping: A useful tool to prevent migration of rectal stents. Endoscopy 2004;36:468.

12. Park SY, Park CH, Cho SB, et al. [The usefulness of clip application in preventing migration of self-expandable metal stent in patients with malignant gastrointestinal obstruction]. Korean J Gastroenterol 2007;49:4-9.

13. Frizzell E, Darwin P. Endoscopic placement of jejunal feeding tubes by using the Resolution clip: Report of 2 cases. Gastrointest Endosc 2006;64:454-6. 
14. Romagnuolo J, Parent J, Vuong T, et al. Predicting residual rectal adenocarcinoma in the surgical specimen after preoperative brachytherapy with endoscopic ultrasound. Can J Gastroenterol 2004; $18: 435-40$.

15. Ohdaira T, Nagai H. Intraoperative localization of early-stage upper gastrointestinal tumors using a magnetic marking clip-detecting system. Surg Endosc 2007;21:810-5.

16. Hameed H, Kalim S, Khan YI. Closure of a nonhealing gastrocutaneous fistula using argon plasma coagulation and endoscopic hemoclips. Can J Gastroenterol 2009;23:217-9.

17. Qadeer MA, Dumont JA, Vargo JJ, Lopez AR, Rice TW. Endoscopic clips for closing esophageal perforations: Case report and pooled analysis. Gastrointest Endosc 2007;66:605-611.

18. Pham BV, Morgan K, Romagnuolo J, et al. Pilot comparison of adhesion formation following colonic perforation and repair in a pig model using a transgastric, laparoscopic, or open surgical technique. Endoscopy 2008;40:664-9.

19. Chuttani R, Barkun A, Carpenter S, et al. Endoscopic clip application devices. Gastrointest Endosc 2006;63:746-50.

20. Maiss J, Hochberger J, Schwab D. Hemoclips: Which is the pick of the bunch? Gastrointest Endosc 2008;67:40-3.

21. Lin HJ, Lo WC, Cheng YC, Perng CL. Endoscopic hemoclip versus triclip placement in patients with high-risk peptic ulcer bleeding. Am J Gastroenterol 2007;102:539-43.

22. Chan CY, Yau KK, Siu WT, et al. Endoscopic hemostasis by using the TriClip for peptic ulcer hemorrhage: A pilot study. Gastrointest Endosc 2008;67:35-9.

23. Maiss J, Dumser C, Zopf Y, et al. "Hemodynamic efficacy" of two endoscopic clip devices used in the treatment of bleeding vessels, tested in an experimental setting using the compact Erlangen Active Simulator for Interventional Endoscopy (compactEASIE) training model. Endoscopy 2006;38:575-80.

24. Jensen DM, Machicado GA, Hirabayashi K. Randomized controlled study of 3 different types of hemoclips for hemostasis of bleeding canine acute gastric ulcers. Gastrointest Endosc 2006;64:768-73.

25. Choi KD, Jung HY, Lee GH, et al. Application of metal hemoclips for closure of endoscopic mucosal resection-induced ulcers of the stomach to prevent delayed bleeding. Surg Endosc 2008;22:1882-6.
26. Howell DA, Eswaran SL, Loew BJ, et al. Use of hemostatic clips in patients undergoing colonoscopy in the setting of coumadin anticoagulation therapy. Gastrointest Endosc 2006;63:AB98. (Abst)

27. Kato H, Fukuchi M, Miyazaki T, et al. Endoscopic clips prevent selfexpandable metallic stent migration. Hepatogastroenterology 2007;54:1388-90.

28. Wu CJ, Hsu PI, Lo GH, et al. Clinical application of clip-assisted endoscopic method for nasoenteric feeding in patients with gastroparesis and gastroesophageal wounds. World J Gastroenterol 2005;11:3714-8.

29. Ginsberg GG, Lipman TO, Fleischer DE. Endoscopic clip-assisted placement of enteral feeding tubes. Gastrointest Endosc 1994;40(2 Pt 1):220-2.

30. Shimizu Y, Kato M, Yamamoto J, et al. Endoscopic clip application for closure of esophageal perforations caused by EMR. Gastrointest Endosc 2004;60:636-9.

31. von Bodegraven AA, Kuipers EJ, Bonenkamp HJ, Meuwissen SG. Esophagopleural fistula treated endoscopically with argon beam electrocoagulation and clips. Gastrointest Endosc 1999;50:407-9.

32. Teitelbaum JE, Gorcey SA, Fox VL. Combined endoscopic cautery and clip closure of chronic gastrocutaneous fistulas. Gastrointest Endosc 2005;62:432-5.

33. John BK, Cortes RA, Feinerman A, Somnay K. Successful closure of a rectovaginal fistula by using an endoscopically placed Resolution clip. Gastrointest Endosc 2008;67:1192-5.

34. Akhras J, Tobi M, Zagnoon A. Endoscopic fibrin sealant injection with application of hemostatic clips: A novel method of closing a refractory gastrocutaneous fistula. Dig Dis Sci 2005;50:1872-4.

35. Gonzalez-Ojeda A, Avalos-Gonzalez J, Mucino-Hernandez MI, et al. Fibrin glue as adjuvant treatment for gastrocutaneous fistula after gastrostomy tube removal. Endoscopy 2004;36:337-41.

36. Eleftheriadis E, Tzartinoglou E, Kotzampassi K, Aletras H. Early endoscopic fibrin sealing of high-output postoperative enterocutaneous fistulas. Acta Chir Scand 1990;156:625-8

37. Valdastri P, Quaglia C, Susilo E, et al. Wireless therapeutic endoscopic capsule: In vivo experiment. Endoscopy 2008;40:979-82. 


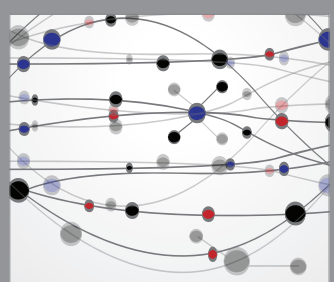

The Scientific World Journal
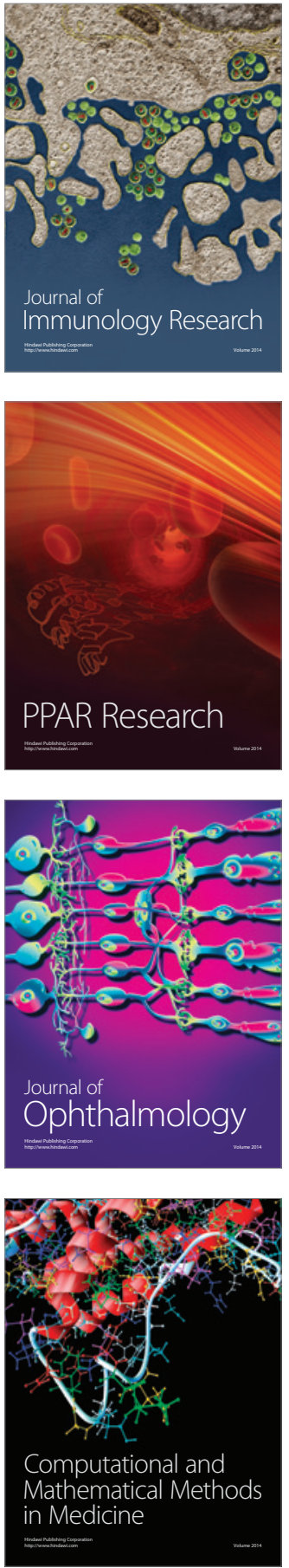

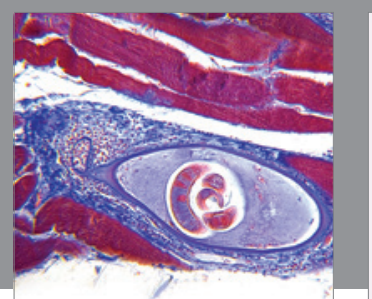

Gastroenterology Research and Practice

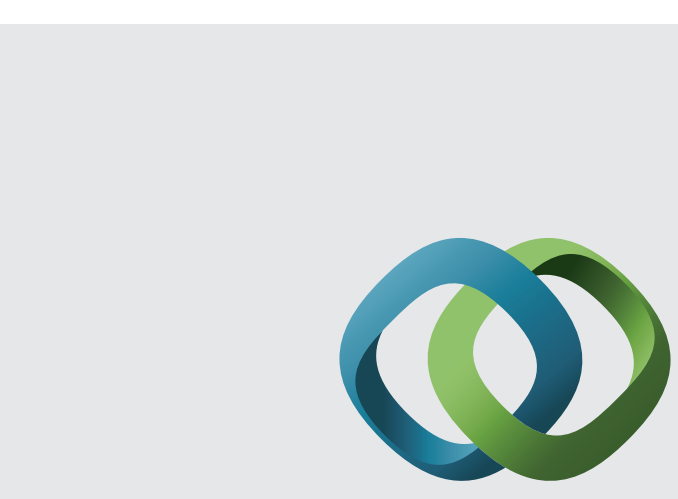

\section{Hindawi}

Submit your manuscripts at

http://www.hindawi.com
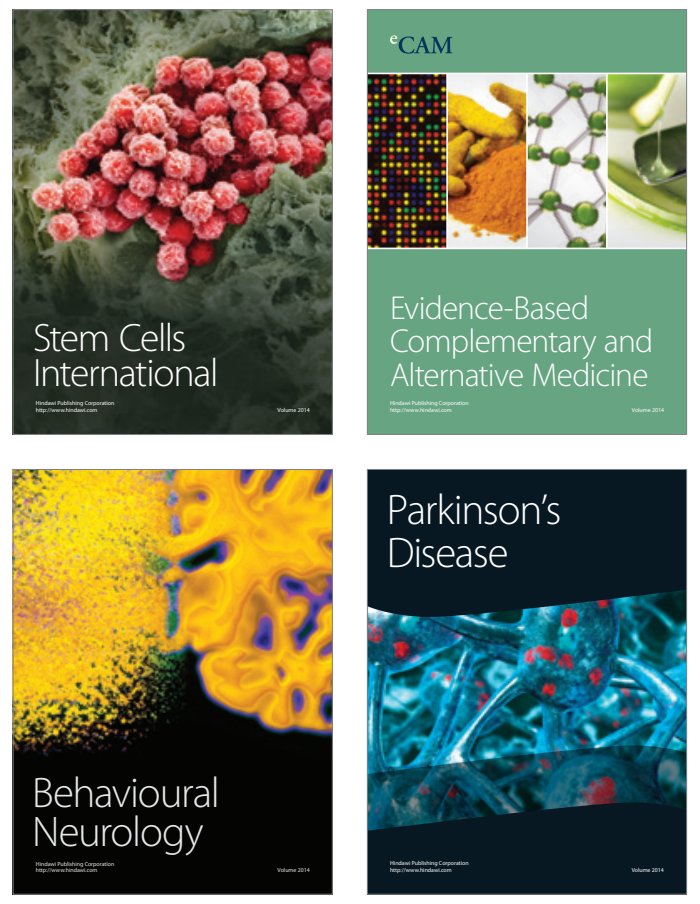
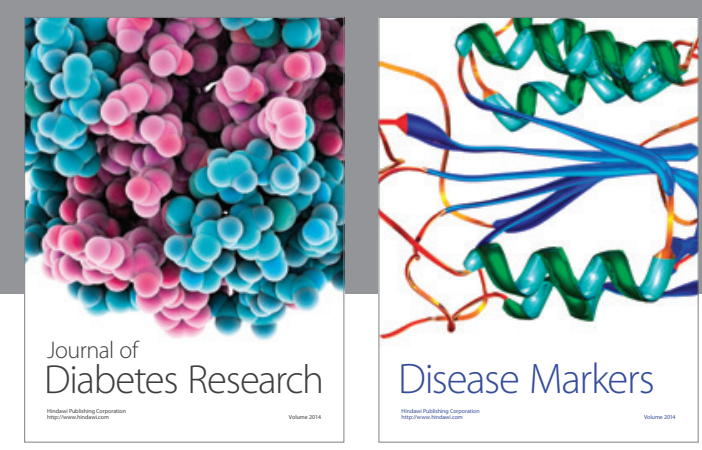

Disease Markers
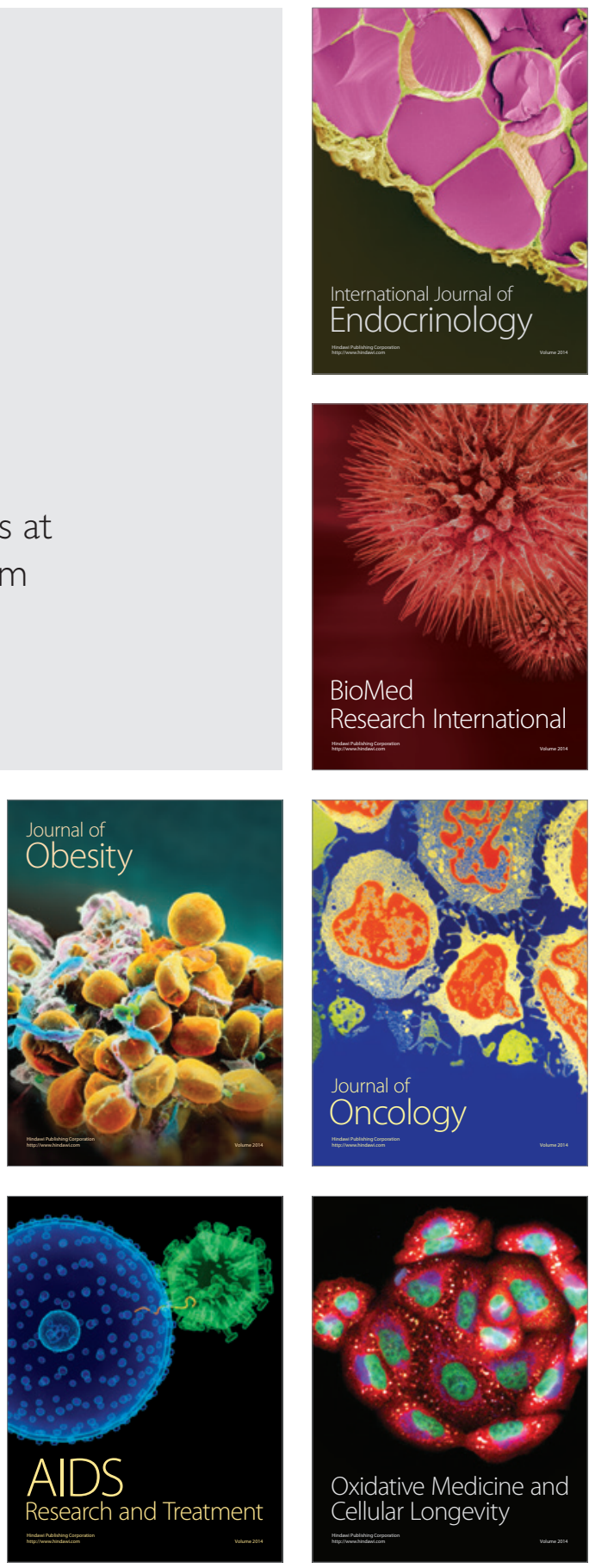